\title{
Effects of a Breastfeeding Support Program on the Prevalence of Exclusive Breastfeeding and Growth in Late Preterm Infants
}

\author{
Gun Ja Jang ${ }^{1}$, Yeon Ran Hong ${ }^{2}$ \\ ${ }^{1}$ Associate Professor, Department of Nursing, Daegu University, Daegu; ${ }^{2}$ Professor, Department of Nursing, Sunchon National University, Sunchon, Korea
}

Purpose: The purpose of this study was to investigate the effects of a breastfeeding support program (BSP) on the prevalence of exclusive breastfeeding and growth in late-preterm infants. Methods: A quasi-experimental study was conducted. The participants were 40 late preterm infants (LPIs), of whom 20 were assigned to the experimental group and 20 to the control group. For the mothers in the experimental group, a BSP was provided prior to the LPIs' discharge and reinforced once a week for 4 weeks. Information on the feeding type was collected by observation and the LPIs' body weight was measured. Results: There were significant differences in feeding type by group and time. Exclusive breastfeeding was 5.18 times more common in the experimental group than in the control group (odds ratio $=5.18,95 \%$ confidence interval $=1.11 \sim 16.70$ ). However, weekly weight gain did not show a significant relationship with group and time $(\mathrm{F}=0.40, p=.712)$. Conclusion: The BSP was helpful for increasing the rate of exclusive breastfeeding in LPIs. Furthermore, the LPIs in the experimental group, which had a higher likelihood of being exclusively breastfed, showed an equivalent amount of weight gain as the LPIs in the control group, in which infants were more likely to be formula-fed.

Key words: Education; Exclusive breastfeeding; Infant formula; Premature infant

\section{Corresponding author Yeon Ran Hong \\ https://orcid.org/0000-0003-2839-1755}

Department of Nursing," Sunchon National University,

255 Jungang-ro, Suncheon 57922, Korea

TEL +82-61-750-3883 FAX +82-61-750-3880

E-MAIL yrhong@sunchon.ac.kr

*This study was supported by the research fund of Daegu University in 2015 (No. 20150417)

Received Dec 9, 2019 Revised Jan 2, 2020 Accepted Jan 8, 2020 (a) This is an Open Access article distributed under the terms of the Creative Commons Attribution NonCommercial License (http://creativecommons.org/licenses/by-nc/4.0/) which permits unrestricted noncommercial use, distribution, and reproduction in any medium, provided the original work is properly cited.

\section{INTRODUCTION}

Late-preterm infants (LPIs), born between 34 weeks and 0 days and 36 weeks and 6 days of gestation [1], account for approximately $70 \%$ of all Korean premature births [2].

Since LPIs are born prior to the maturation of many body organs and systems, they are especially protected by the bioactive components in human milk and breast milk reduces the risk of short-term and long-term morbidities through the nutritional, anti-infective, and antioxidative substances that it contains [3]. However, LPIs are at a greater risk for poor breastfeeding outcomes, including delayed breastfeeding initiation [4-8], early breastfeeding cessation [9,10], challenging experiences of breastfeeding [9,11], and lower rates of breastfeeding than term infants $[5,12,13]$ and preterm infants born at less than 34 weeks of gestation [14,15].

To initiate successful breastfeeding, LPIs are put on their mothers' breast within an hour post-birth and have access the breast at least 8 to 12 times per day. However, LPIs are more likely than term infants to have hypothermia, hypoglycemia, hyperbilirubinemia, or feeding difficulties requiring special care or management in the neonatal intensive care unit (NICU) at birth $[6,16,17]$. As a result of medical issues and LPIs' separation from their mothers during NICU admission, 
initial feeding is often delayed by several hours or even days. Consequently, supplementation with formula is common during hospitalization $[6,18]$, and the rate of breastfeeding initiation in LPIs has been reported to be 59 70\% [7], which is lower than that of term infants [5]. The exclusive breastfeeding rate during hospitalization and at hospital discharge has been reported to be only $28 \sim 43 \%[6,18]$.

LPIs are also at risk for early breastfeeding cessation, as shown by the finding that the average breastfeeding duration of LPIs was 3.6 months [13]. The leading reasons reported by mothers of LPIs for early breastfeeding cessation were perceived inadequate milk supply and breastfeeding difficulties $[9,19,20]$. Mothers of LPIs are especially likely to have medical issues such as placental abruption, diabetes, thyroid problems, or delivery by cesarean section [21]. These issues can lead to delayed lactogenesis II, which causes poor milk production and secretion [21]. Therefore, a breastfeeding support program (BSP) for the mothers of LPIs specialized in stimulating breast milk production during the early stages of postpartum. To establish and maintain exclusive breastfeeding in LPIs by 6 months of corrected age, breastfeeding support and education for their mothers aims to protect the maternal milk supply and to alleviate breastfeeding difficulties. Test-weighing infants before and after each breastfeed was found to be a good way to improve breastfeeding confidence in mothers [22].

According to a recent study [12], hospital breastfeeding support increased the likelihood of exclusive breastfeeding after discharge by 2.2 times, but only $16.4 \%$ of mothers of LPIs received hospital breastfeeding support, compared with 30.7\% of term infants. Furthermore, mothers of LPIs indicated inadequate lactation support from healthcare experts after discharge [9]. LPIs in the NICU, and even in the full-term nursery, are rarely directly breastfed during hospitalization in Korea. Consequently, the majority of LPIs' mothers are discharged without adequate lactation support or substantial breastfeeding practice.

Thus, the purpose of this study was to investigate the effects of a BSP on the prevalence of exclusive breastfeeding and weekly weight gain in late-preterm infants for 4 weeks after hospital discharge.

\section{METHODS}

\section{Study Design and Participants}

This study utilized a quasi-experimental design with a time -series, and data were collected four times after LPIs' discharge. PASS 2008 was used to calculate the required sample size. The following criteria were considered: a significance level of $5 \%$, a power of $80 \%$, the presence of two parallel groups with four sets of repeated measures, and breastfeeding proportions in the experimental and control group of $50 \%$ and $20 \%$, respectively. Based on these assumptions, the required sample size was calculated to be 36 LPIs and the targeted sample size was $40 \mathrm{LPIs}$, anticipating a 10\% dropout rate. The participants consisted of 40 LPIs hospitalized in a nursery or NICU of one hospital in Daegu city between March 2015 and January 2016. Twenty LPIs and 16 of their mothers were assigned to the experimental group, and twenty LPIs and 16 of their mothers to the control group. The unequal number of LPIs and their mothers in both groups resulted from mothers with twins.

The inclusion criteria were as follows: a) mothers who had the intention to breast-feed; $b$ ) mothers who provided consent for data collection at their home during the 4-week period after the LPIs' discharge; c) if multiparous, mothers who had not breastfed before; d) LPIs with 5-minute APGAR scores $\geq$ 7; and e) LPIs with development appropriate for gestational age (between the 10th and 90th percentile on the growth chart). The exclusion criteria for LPIs were as follows: a) delayed oral feeding for over 3 days due to a serious respiratory problem or surgical operation; b) continued feeding intolerance (feeding was deferred at least 4 times a day) over 3 days; and c) delayed discharge due to clinical outcomes of the newborn, such as severe hyperbilirubinemia or sepsis.

\section{Study Procedures}

Institutional Review Board (IRB) approval was obtained at the hospital (DFH15ORIO259). Medical records were reviewed for mothers' and LPIs' demographic information and feeding-related characteristics prior to discharge. The feeding type (exclusive breastfeeding, mixed feeding, and formula feeding) was observed at home every week for 4 weeks after LPIs' discharge. The first few weeks after LPIs' discharge are a crucial period of transition from any feeding into exclusive breastfeeding, so LPIs' mothers were provided with breastfeeding support on a weekly basis. Mothers in both groups received home visits from the same researcher, a certified lactation consultant, once a week for 4 weeks. LPIs' body weight was measured using an electric scale (CAS Computing Scale, CAS Corp., Gyeonggi-do, Korea) at each of the four weekly visits.

At the hospital where data were collected, a nurse attempted to feed the LPIs within 1 hour after birth in cases of a normal vaginal delivery and within 3 hours after birth in cases of a cesarean section delivery to determine whether they showed any health problems. LPIs in the NICU were also bottle-fed due to their mothers' earlier discharge. At discharge, the majority of LPIs received mixed feeding, with a combina- 
tion of expressed breast milk and formula.

On the day of the LPIs' discharge, a nurse researcher provided the BSP to the mothers in the experimental group, whereas the mothers in the control group were given the home visit schedule and counseling related to nurturing the LPIs by the same researcher. Additionally, at each subsequent home visit, the mothers in the experimental group again received reinforcement of the BSP and the mothers in the control group received counseling on nurturing skills for LPIs. The feeding type was observed and the LPIs' body weight was measured at every home visit (Figure 1).

\section{Breastfeeding Support Program}

This program consisted of a web-based breastfeeding education program (http:// momfeed.co.kr/) and practical breastfeeding support based on LPIs' feeding ability and mothers' health issues once a week from the first week to the fourth week, provided by the researcher at home visits. The mothers of LPIs in the experimental group were instructed on regular pumping to stimulate breastmilk production instead of having their infants attempt to latch at the first and second visits, because most LPIs did not have sufficient sucking power for direct breastfeeding [7]. At third and fourth week, LPIs' moth- ers were taught how to encourage their infants to latch and to properly breastfeed, with the aim of establishing exclusive breastfeeding. The appropriateness of this intervention was verified by three International Board Certified Lactation Consultants who had worked in obstetric wards for more than 10 years. Just after completing data collection, the website was shut down due to its high maintenance costs. This web-site was only available for program managers, so mothers in the experimental group were only able to access it at the researcher's home visits.

\section{Feeding Types}

The following three categories of feeding types were defined: exclusive feeding, mixed feeding, and formula feeding.

- Exclusive breastfeeding: LPIs were exclusively breastfed via direct feeding at the breast, not bottles containing expressed breast milk.

- Mixed feeding: LPIs were partly breastfed and partly received supplementation with formula. Breastfeeding was done through direct breastfeeding and/or bottles containing breast milk.

- Formula feeding: LPIs were exclusively formula-fed.

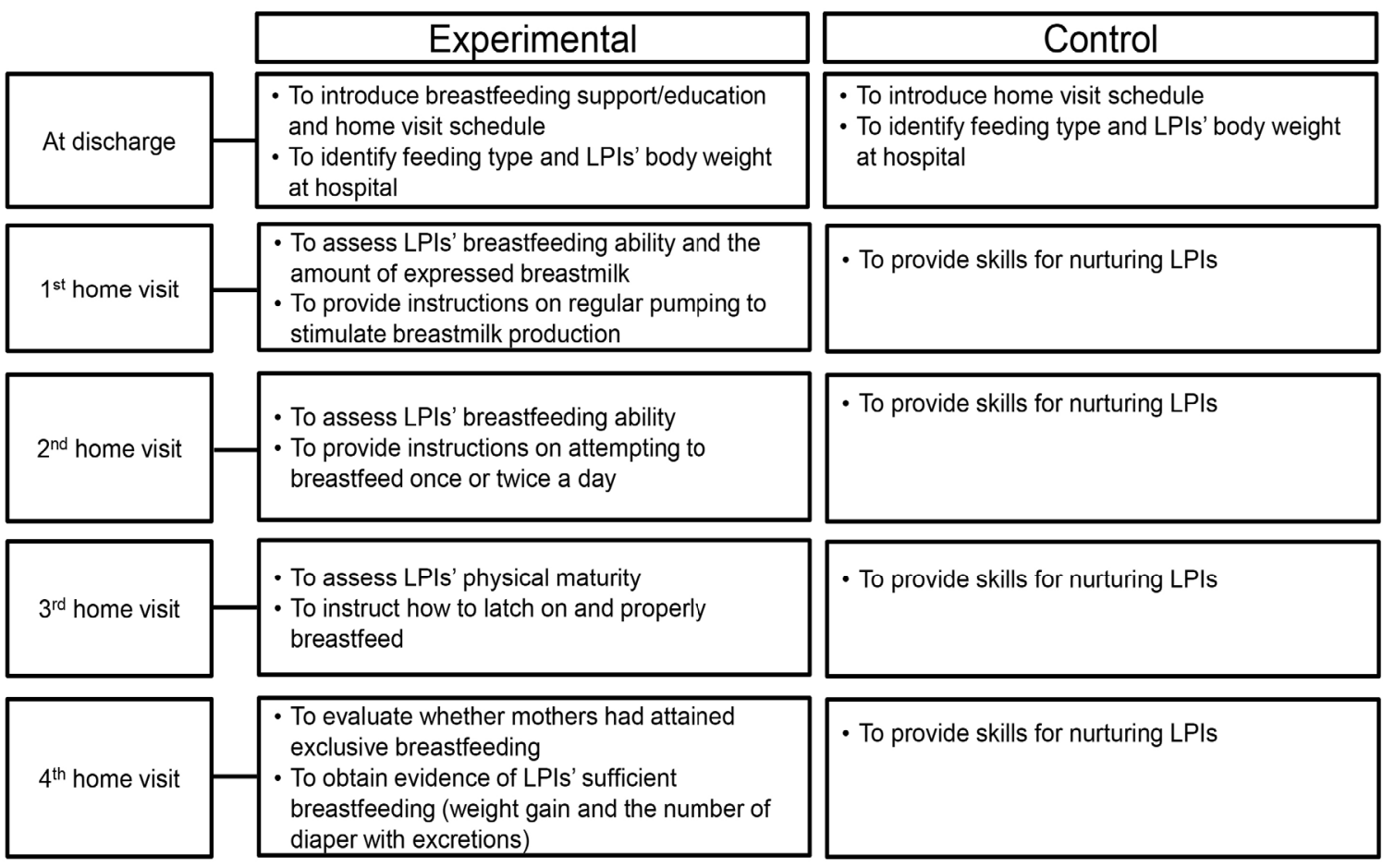

Feeding type and LPls' body weight were investigated every home visit by a researcher both experimental and control group. LPls=Late preterm infants.

Figure 1. Study procedures. 


\section{Data Analysis}

Data were analyzed using SAS version 9.4 (SAS Institute Inc., Cary, NC, USA). Descriptive and inferential statistical analyses were performed in order to compare the demographic characteristics of participants between the two groups. The $x^{2}$ test was used to compare feeding types between the two groups at each week for 4 weeks. As the feeding type for the 4 weeks after discharge was repeatedly measured over time, the effects of BSP on exclusive feeding were analyzed by generalized estimating equations (GEE), and weekly weight gain by repeated-measures ANOVA. For the GEE analysis, feeding type was transformed into a binary variable by grouping formula feeding and mixed feeding together, versus exclusive feeding.

\section{RESULTS}

\section{Homogeneity Test of Demographic Characteristics be- tween the Two Groups}

The maternal and LPI characteristics showed no statistically significant differences between the experimental and control groups (Table 1). The mothers' average age in the experimental and control groups was 32.3 and 34.0 years, respectively. Nine mothers in each group gave birth by cesarean section. The mean total length of the LPIs' hospital stays in the experimental and control groups was 7.70 and 9.25 days, respectively. The average birth weight in the experimental and control group was 2,228.0 $\mathrm{g}$ and 2,481.5 g, respectively. Eighteen LPIs in the experimental group and 15 LPIs in the

Table 1. Homogeneity Test of Demographic Characteristics between the Two Groups

\begin{tabular}{|c|c|c|c|c|c|}
\hline \multirow{2}{*}{ Variables } & \multirow{2}{*}{ Categories } & \multirow{2}{*}{$\begin{array}{c}\text { Exp. }(\mathrm{n}=20) \\
\mathrm{n}(\%) \text { or } \mathrm{M} \pm \mathrm{SD}\end{array}$} & \multirow{2}{*}{$\begin{array}{c}\text { Cont. }(\mathrm{n}=20) \\
\mathrm{n}(\%) \text { or } \mathrm{M} \pm \mathrm{SD}\end{array}$} & \multirow{2}{*}{$x^{2}$ or $\mathrm{t}$} & \multirow{2}{*}{$p$} \\
\hline & & & & & \\
\hline Maternal age (year) & & $32.3 \pm 2.5$ & $34.0 \pm 2.9$ & 1.83 & .077 \\
\hline Type of delivery & $\begin{array}{l}\text { Vaginal } \\
\text { Cesarean }\end{array}$ & $\begin{array}{l}7(43.8) \\
9(56.2)\end{array}$ & $\begin{array}{l}7(43.8) \\
9(56.2)\end{array}$ & 0.00 & $>.999$ \\
\hline Maternal parity & $\begin{array}{l}\text { Primiparous } \\
\text { Multiparous }\end{array}$ & $\begin{array}{r}14(87.5) \\
2(12.5)\end{array}$ & $\begin{array}{r}12(75.0) \\
4(25.0)\end{array}$ & 0.82 & .654 \\
\hline Maternal employment & $\begin{array}{l}\text { No } \\
\text { Yes }\end{array}$ & $\begin{array}{r}12(75.0) \\
4(25.0)\end{array}$ & $\begin{array}{r}12(75.0) \\
4(25.0)\end{array}$ & 0.00 & $>.999$ \\
\hline Maternal health problem & $\begin{array}{l}\text { No } \\
\text { Yes }\end{array}$ & $\begin{array}{r}11(68.8) \\
5(31.2)\end{array}$ & $\begin{array}{r}12(75.0) \\
4(25.0)\end{array}$ & 0.16 & $>.999$ \\
\hline Length of infant's hospital stay (day) & & $7.70 \pm 3.88$ & $9.25 \pm 3.99$ & 1.25 & .220 \\
\hline Infant's sex & $\begin{array}{l}\text { Male } \\
\text { Female }\end{array}$ & $\begin{array}{l}10(50.0) \\
10(50.0)\end{array}$ & $\begin{array}{r}9(45.0) \\
11(55.0)\end{array}$ & 0.10 & $>.999$ \\
\hline Singleton/twin & $\begin{array}{l}\text { Singleton } \\
\text { Twin }\end{array}$ & $\begin{array}{r}12(60.0) \\
8(40.0)\end{array}$ & $\begin{array}{r}11(55.0) \\
9(45.0)\end{array}$ & 0.10 & $>.999$ \\
\hline Infant's gestational age (week) & $\begin{array}{l}34 \\
35 \\
36\end{array}$ & $\begin{array}{l}7(35.0) \\
7(35.0) \\
6(30.0)\end{array}$ & $\begin{array}{l}6(30.0) \\
8(40.0) \\
6(30.0)\end{array}$ & 0.14 & .931 \\
\hline Infant's birth weight $(\mathrm{g})$ & & $2,228.0 \pm 315.3$ & $2,481.5 \pm 383.7$ & 1.29 & .204 \\
\hline Disease of newborn & $\begin{array}{l}\text { No } \\
\text { Yes }\end{array}$ & $\begin{array}{l}10(50.0) \\
10(50.0)\end{array}$ & $\begin{array}{r}7(35.0) \\
13(65.0)\end{array}$ & 0.92 & .523 \\
\hline Infant's NICU admission & $\begin{array}{l}\text { No } \\
\text { Yes }\end{array}$ & $\begin{array}{r}11(55.0) \\
9(45.0)\end{array}$ & $\begin{array}{l}10(50.0) \\
10(50.0)\end{array}$ & 0.10 & $>.999$ \\
\hline Day of first feeding & $\begin{array}{l}\text { At birth } \\
\text { After birth }\end{array}$ & $\begin{array}{r}18(90.0) \\
2(10.0)\end{array}$ & $\begin{array}{r}15(75.0) \\
5(25.0)\end{array}$ & 1.56 & .407 \\
\hline Tube/supportive feeding & $\begin{array}{l}\text { No } \\
\text { Yes }\end{array}$ & $\begin{array}{r}16(80.0) \\
4(20.0)\end{array}$ & $\begin{array}{r}16(80.0) \\
4(20.0)\end{array}$ & 0.00 & $>.999$ \\
\hline Feeding intolerance & $\begin{array}{l}\text { No } \\
\text { Yes }\end{array}$ & $\begin{array}{r}18(90.0) \\
2(10.0)\end{array}$ & $\begin{array}{r}15(75.0) \\
5(25.0)\end{array}$ & 1.56 & .407 \\
\hline
\end{tabular}

Exp.=Experimental group; Cont. $=$ Control group; $\mathrm{NICU}=\mathrm{Neonatal}$ intensive care unit. 
control group were first fed with formula at birth. A majority of the LPIs had no feeding tolerance, and four LPIs in each group were fed with supportive feeding techniques, such as cup or tube feeding.

\section{Differences in Breastfeeding Prevalence between the Two Groups}

Mixed feeding at discharge steadily transitioned into exclusive breastfeeding or formula feeding over time. The exclusive breastfeeding rate in the experimental group $(55.0 \%)$ was significantly higher than that in the control group $(25.0 \%)$ at the fourth week $\left(x^{2}=6.47, p=.039\right)$ (Table 2).

\section{Comparison of the Probability of Exclusive Breastfeed- ing by Group and Time}

A statistically significant difference between the groups was found in terms of whether the LPIs engaged in "exclusive breastfeeding" or "mixed or formula feeding" (odds ratio [OR]
$=5.18,95 \%$ confidence interval $[\mathrm{CI}]=1.11 \sim 16.70)$. Furthermore, when comparing "exclusive breastfeeding" to "mixed or formula feeding" by time, statistically significant differences were found at the second week $(\mathrm{OR}=7.05,95 \% \mathrm{CI}=1.66 \sim 29.90)$, third week $(\mathrm{OR}=11.98,95 \% \mathrm{CI}=2.71 \sim 52.89)$, and fourth week $(\mathrm{OR}=15.21,95 \% \mathrm{CI}=3.34 \sim 69.19)$. However, no statistically significant differences were found according to the interaction between group and time (Table 3).

\section{Differences in Late-preterm Infants' Weekly Weight Gain between the Two Groups}

No significant differences in the LPIs' weekly weight gain were found by group $(\mathrm{F}=0.01, p=.912)$, time $(\mathrm{F}=1.83, p=.158)$, and the interaction of group and time $(\mathrm{F}=0.40, p=.712)$ (Table 4$)$.

\section{DISCUSSION}

This was the first study in Korea to develop a BSP for mothers with LPIs and to determine the effect of the BSP on ex-

Table 2. Comparison of Feeding Types after Discharge between the Two Groups

$(N=40)$

\begin{tabular}{|c|c|c|c|c|c|}
\hline Time & Feeding type & Exp. $(n=20)$ & Cont. $(n=20)$ & $x^{2}$ & $p$ \\
\hline At discharge & $\begin{array}{l}\text { Formula } \\
\text { Mixed }\end{array}$ & $\begin{array}{r}6(30.0) \\
14(70.0)\end{array}$ & $\begin{array}{r}7(35.0) \\
13(65.0)\end{array}$ & 1.08 & .584 \\
\hline At the first week & $\begin{array}{l}\text { Exclusive breastfeeding } \\
\text { Formula } \\
\text { Mixed }\end{array}$ & $\begin{array}{r}2(10.0) \\
6(30.0) \\
12(60.0)\end{array}$ & $\begin{array}{r}2(10.0) \\
4(20.0) \\
14(70.0)\end{array}$ & 0.55 & .758 \\
\hline At the second week & $\begin{array}{l}\text { Exclusive breastfeeding } \\
\text { Formula } \\
\text { Mixed }\end{array}$ & $\begin{array}{l}8(40.0) \\
5(25.0) \\
7(35.0)\end{array}$ & $\begin{array}{r}2(10.0) \\
5(25.0) \\
13(65.0)\end{array}$ & 5.40 & .067 \\
\hline At the third week & $\begin{array}{l}\text { Exclusive breastfeeding } \\
\text { Formula } \\
\text { Mixed }\end{array}$ & $\begin{array}{l}9(45.0) \\
5(25.0) \\
6(30.0)\end{array}$ & $\begin{array}{r}5(25.0) \\
12(60.0) \\
3(15.0)\end{array}$ & 5.03 & .081 \\
\hline At the fourth week & $\begin{array}{l}\text { Exclusive breastfeeding } \\
\text { Formula } \\
\text { Mixed }\end{array}$ & $\begin{array}{r}11(55.0) \\
5(25.0) \\
4(20.0)\end{array}$ & $\begin{array}{r}5(25.0) \\
13(65.0) \\
2(10.0)\end{array}$ & 6.47 & .039 \\
\hline
\end{tabular}

Exp.=Experimental group; Cont.=Control group.

Table 3. Comparison of Probability of Exclusive Breastfeeding by Group and Time

\begin{tabular}{llcccccc}
\hline Variables & Categories & Estimate & SE & OR & 95\% CI & $z$ & \\
\hline Group & Control & 1.00 & & & & & \\
& Experimental & 1.64 & 0.79 & 5.18 & $1.11 \sim 16.70$ & 2.08 & \\
Time & Discharge & 1.00 & & & & & \\
& First week & 0.78 & 0.57 & 2.18 & $0.71 \sim 6.66$ & 1.37 & .171 \\
& Second week & 1.95 & 0.74 & 7.05 & $1.66 \sim 29.90$ & 2.65 & .008 \\
& Third week & 2.48 & 0.76 & 11.98 & $2.71 \sim 52.89$ & 3.28 & .001 \\
& Fourth week & 2.72 & 0.77 & 15.21 & $3.34 \sim 69.19$ & 3.52 & $<.001$ \\
\hline
\end{tabular}

The interaction of group and time showed no statistically significant difference in a generalized estimated equation analysis; OR=Odds ratio; $95 \%$ $\mathrm{CI}=95 \%$ Confidence interval. 
Table 4. Comparison of Weekly Weight Gain between the Two Groups

$(N=40)$

\begin{tabular}{lccccccc}
\hline Group & First week & Second week & Third week & Fourth week & & F & $p$ \\
\hline Experimental & $245.5 \pm 108.3$ & $266.0 \pm 112.1$ & $295.0 \pm 65.2$ & $268.5 \pm 213.1$ & Group & 0.01 & .912 \\
Control & $226.5 \pm 96.4$ & $272.0 \pm 99.9$ & $279.5 \pm 93.9$ & $303.5 \pm 101.5$ & Time & 1.83 & .158 \\
& & & & & & Group*Time & 0.40 \\
\hline
\end{tabular}

clusive feeding in LPIs from discharge to the fourth week after discharge. The BSP, a vital program for establishing exclusive breastfeeding in LPIs, was developed to reinforce and supplement breastfeeding education during LPIs' hospitalization, as there are few standard guidelines for breastfeeding LPIs. This study also expanded upon the limitations of previous studies, which analyzed feeding types based on mothers' self-reports, rather than on reliable findings obtained through direct observations.

Almost all the LPIs in this study were first fed with formula at birth. The reason for first supplying LPIs with formula was that healthcare experts hesitated to have LPIs nurse at their mothers' breast immediately after birth due to their insufficient coordination of sucking, swallowing, and respiration; therefore, the healthcare experts were likely to add fortified formula for weight gain [8]. This hesitancy results in mothers of LPIs having fewer opportunities for breastfeeding support than mothers of term infants [8]. In particular, mothers of LPIs admitted to the NICU are likely to have the fewest opportunities for breastfeeding education and support due to their separation from the LPIs.

Before providing the intervention, as baseline data, feeding type at the time of hospital discharge was not significantly different between the two groups. There were no cases of exclusive breastfeeding in either group, demonstrating that the breastfeeding education for mothers with LPIs provided by healthcare experts was insufficient in Korea's clinical setting and thereby confirming the necessity of postpartum breastfeeding education to supplement the breastfeeding education provided during hospitalization. It is especially necessary and actually vital to have a BSP as part of the standard breastfeeding protocol for mothers of LPIs. The usual practice of breastfeeding education in Korea through video clips and one or two demonstrations that are provided just before hospital discharge are weak substitutes for mothers who need more hands-on practice.

One of the most important results of this study was that the BSP provided to the experimental group was effective for increasing the prevalence of exclusive breastfeeding at the fourth week after discharge. For instance, the exclusive breastfeeding rate in the experimental group increased by $45.0 \%$ from two LPIs $(10.0 \%)$ at the first week to 11 LPIs (55.0\%) at the fourth week after discharge, whereas the rate of formula feed- ing decreased by $5.0 \%$ from six LPIs $(30.0 \%)$ at the first week to five LPIs $(25.0 \%)$ at the fourth week. In contrast, the exclusive breastfeeding rate in the control group increased by $15.0 \%$ from two LPIs $(10.0 \%)$ at the first week to five LPIs $(25.0 \%)$ at the fourth week, while the rate of formula feeding also increased by $45.0 \%$ from four LPIs $(20.0 \%)$ at the first week to 13 LPIs (65.0\%) at the fourth week after discharge. The BSP demonstrated a positive association with a transition to exclusive breastfeeding from mixed feeding. Practical latching and feeding support based on LPIs' feeding ability and physical maturity contributed to an increased breastfeeding prevalence in the early period of the feeding transition. Moreover, the breastfeeding support provided at the nurse researcher's home visits played an important role in ensuring that the LPIs' mothers felt supported. This was consistent with the finding of Rayfield et al. [8] that mothers of LPIs who received sufficient help with breastfeeding and breastfeeding support in the hospital were more likely to breastfeed than those who did not receive any help with breastfeeding. Likewise, the present study found that LPIs whose mothers were provided with postpartum breastfeeding education were more likely to be exclusively fed for 4 weeks after discharge.

In a comparison of the likelihood of exclusive feeding by time and group, a significant difference between the two groups appeared from the second week to the fourth week after discharge. In other words, the LPIs in the experimental group were more likely to exclusively breastfeed than those in the control group. Most previous studies reported an early cessation of breastfeeding and lowered prevalence of breastfeeding for LPIs $[5,9,10,12,13]$. However, this study showed that postpartum breastfeeding education was considerably useful in establishing exclusive feeding at the breast.

No significant between-group difference over time was found in the weekly weight gain of LPIs. In other words, the weight gain of breastfeeding LPIs was equivalent to that of formula-fed LPIs. Ensuring that LPIs are sufficiently breastfed during the critical period of a few weeks after discharge is thought to yield positive results in terms of weight gain. This is consistent with the findings of Meier, Furman, and Degenhardt [23] that the expectation of weight gain helped mothers exclusively breastfeed instead of pumping and the finding of Kent et al. [22] that measuring breast milk production by testweighing infants before and after each breastfeed improved 
mothers' breastfeeding confidence.

Despite the differences across various clinical settings in terms of breastfeeding for LPIs, this study demonstrated that the breastfeeding support provided by a BSP enhanced the breastfeeding rate for LPIs.

\section{CONCLUSION}

The BSP developed for LPIs showed considerable effectiveness in enhancing exclusive breastfeeding. The BSP was especially useful for changing from mixed feeding at hospital discharge to exclusive feeding at the breast at the fourth week after discharge. In this study, exclusive breastfeeding did not refer to bottle feeding using expressed breast milk, but instead to directly feeding at the mothers' breast exclusively. Because breastfeeding education is a nursing task in Korea, a BSP can be utilized to establish successful breastfeeding for LPIs in clinical settings.

\section{Conflict of interest}

No existing or potential conflict of interest relevant to this article was reported.

\section{REFERENCES}

1. Engle WA. A recommendation for the definition of "late preterm" (near-term) and the birth weight-gestational age classification system. Seminars in Perinatology. 2006;30(1):2-7. https://doi.org/10.1053/j.semperi.2006.01.007

2. Statistics Korea. 2014 Live births by period of pregrancy [Internet]. Daejeon: Statistics Korea; 2015 [cited 2016 March 20]. Available from:

http://kosis.kr/eng/statisticsList/statisticsListIndex.do?menuId =M_01_01\&vwcd=MT_ETITLE\&parmTabId=M_01_01\&statId= 1962001\&themaId=\#SelectStatsBoxDiv

3. Meier P, Patel AL, Wright K, Engstrom JL. Management of breastfeeding during and after the maternity hospitalization for late preterm infants. Clinics in Perinatology. 2013;40(4):689-705.

https://doi.org/10.1016/j.clp.2013.07.014

4. Ayton J, Hansen E, Quinn S, Nelson M. Factors associated with initiation and exclusive breastfeeding at hospital discharge: Late preterm compared to 37 week gestation mother and infant cohort. International Breastfeeding Journal. 2012;7(1):16. https://doi.org/10.1186/1746-4358-7-16

5. Demirci JR, Sereika SM, Bogen D. Prevalence and predictors of early breastfeeding among late preterm mother-infant dyads. Breastfeeding Medicine. 2013;8(3):277-285.

https://doi.org/10.1089/bfm.2012.0075

6. Medoff Cooper B, Holditch-Davis D, Verklan MT, Fraser-Askin D,
Lamp J, Santa-Donato A, et al. Newborn clinical outcomes of the AWHONN late preterm infant research-based practice project. Journal of Obstetric, Gynecologic, and Neonatal Nursing. 2012; 41(6):774-785. https://doi.org/10.1111/j.1552-6909.2012.01401.x

7. Radtke JV. The paradox of breastfeeding-associated morbidity among late preterm infants. Journal of Obstetric, Gynecologic, and Neonatal Nursing. 2011;40(1):9-24.

https://doi.org/10.1111/j.1552-6909.2010.01211.x

8. Rayfield S, Oakley L, Quigley MA. Association between breastfeeding support and breastfeeding rates in the UK: A comparison of late preterm and term infants. BMJ Open. 2015;5(11):e009144. https://doi.org/10.1136/bmjopen-2015-009144

9. Kair LR, Flaherman VJ, Newby KA, Colaizy TT. The experience of breastfeeding the late preterm infant: A qualitative study. Breastfeeding Medicine. 2015;10(2):102-106. https://doi.org/10.1089/bfm.2014.0121

10. Natarajan G, Shankaran S. Short- and long-term outcomes of moderate and late preterm infants. American Journal of Perinatology. 2016;33(3):305-317. https://doi.org/10.1055/s-0035-1571150

11. Ikonen R, Paavilainen E, Kaunonen M. Preterm infants' mothers' experiences with milk expression and breastfeeding: An integrative review. Advances in Neonatal Care. 2015;15(6):394-406. https://doi.org/10.1097/ANC.0000000000000232

12. Goyal NK, Attanasio LB, Kozhimannil KB. Hospital care and early breastfeeding outcomes among late preterm, early-term, and term infants. Birth. 2014;41(4):330-338.

https://doi.org/10.1111/birt.12135

13. Hackman NM, Alligood-Percoco N, Martin A, Zhu J, Kjerulff KH. Reduced breastfeeding rates in firstborn late preterm and early term infants. Breastfeeding Medicine. 2016;11(3):119-125. https:// doi.org/10.1089/bfm.2015.0122

14. Colaizy TT, Morriss FH. Positive effect of NICU admission on breastfeeding of preterm US infants in 2000 to 2003. Journal of Perinatology. 2008;28:505-510. https://doi.org/10.1038/jp.2008.32

15. Jang GJ, Lee SL, Kim HM. Breast feeding rates and factors influencing breast feeding practice in late preterm infants: Comparison with preterm born at less than 34 weeks of gestational age. Journal of Korean Academy of Nursing. 2012;42(2):181-189.

https://doi.org/10.4040/jkan.2012.42.2.181

16. Engle WA, Tomashek KM, Wallman C; the Committee on Fetus and Newborn. "Late-preterm" infants: A population at risk. Pediatrics. 2007;120(6):1390-1401. https:// doi.org/10.1542/ peds.2007-2952

17. Na JY, Park N, Kim ES, Lee HJ, Shim GH, Lee JA, et al. Short-term clinical outcomes of late preterm infants. Korean Journal of Pediatrics. 2009;52(3):303-309. https://doi.org/10.3345/kjp.2009.52.3.303

18. Mattsson E, Funkquist EL, Wickström M, Nyqvist KH, Volgsten H. Healthy late preterm infants and supplementary artificial milk feeds: Effects on breast feeding and associated clinical parameters. 
Midwifery. 2015;31(4):426-431.

https://doi.org/10.1016/j.midw.2014.12.004

19. McDonald SW, Benzies KM, Gallant JE, McNeil DA, Dolan SM, Tough SC. A comparison between late preterm and term infants on breastfeeding and maternal mental health. Maternal and Child Health Journal. 2013;17(8):1468-1477.

https://doi.org/10.1007/s10995-012-1153-1

20. McNeil DA, Siever J, Tough S, Yee W, Rose MS, Lacaze-Masmonteil T. Hospital re-admission of late preterm or term infants is not a factor influencing duration of predominant breastfeeding. Archives of Disease in Childhood. Fetal and Neonatal Edition. 2013;98 (2):F145-F150. https://doi.org/10.1136/archdischild-2011-300889

21. Briere C, Lucas R, McGrath JM, Lussier M, Brownell E. Estab- lishing breastfeeding with the late preterm infants in the NICU. Journal of Obstetric, Gynecologic, and Neonatal Nursing. 2015;44 (1):102-113. https:// doi.org/10.1111/1552-6909.12536

22. Kent JC, Hepworth AR, Langton DB, Hartmann PE. Impact of measuring milk production by test weighing on breastfeeding confidence in mothers of term infants. Breastfeeding Medicine. 2015;10(6):318-325. https://doi.org/10.1089/bfm.2015.0025

23. Meier PP, Furman LM, Degenhardt M. Increased lactation risk for late preterm infants and mothers: Evidence and management strategies to protect breastfeeding. Journal of Midwifery and Women's Health. 2007;52(6):579-587.

https://doi.org/10.1016/j.jmwh.2007.08.003 